\title{
Zinc Gluconate Induces Potentially Cancer Chemopreventive Activity in Barrett's Esophagus: A Phase 1 Pilot Study
}

\author{
M. C. Valenzano ${ }^{3} \cdot$ E. Rybakovsky ${ }^{3} \cdot$ V. Chen ${ }^{1} \cdot$ K. Leroy ${ }^{1} \cdot$ J. Lander $^{1} \cdot$ E. Richardson ${ }^{1} \cdot$ S. Yalamanchili ${ }^{1} \cdot$ S. McShane ${ }^{1}$. \\ A. Mathew ${ }^{1} \cdot$ B. Mayilvaganan ${ }^{1} \cdot$ L. Connor ${ }^{1} \cdot$ R. Urbas ${ }^{1} \cdot$ W. Huntington ${ }^{1} \cdot$ A. Corcoran ${ }^{1} \cdot$ S. Trembeth ${ }^{1}$. \\ E. McDonnell ${ }^{1}$. P. Wong ${ }^{1}$. G. Newman ${ }^{1}$ - G. Mercogliano ${ }^{1} \cdot$ M. Zitin ${ }^{1}$ - B. Etemad ${ }^{1}$. J. Thornton ${ }^{1} \cdot$ G. Daum ${ }^{2} \cdot$ J. Raines $^{3}$. \\ A. Kossenkov ${ }^{4} \cdot$ L. Y. Fong ${ }^{5} \cdot$ J. M. Mullin ${ }^{1,3,6}$
}

Received: 19 November 2019 / Accepted: 2 May 2020 / Published online: 15 May 2020

(c) The Author(s) 2020

\begin{abstract}
Background Chemopreventive effects of zinc for esophageal cancer have been well documented in animal models. This prospective study explores if a similar, potentially chemopreventive action can be seen in Barrett's esophagus (BE) in humans. Aims To determine if molecular evidence can be obtained potentially indicating zinc's chemopreventive action in Barrett's metaplasia.

Methods Patients with a prior BE diagnosis were placed on oral zinc gluconate (14 days of $26.4 \mathrm{mg}$ zinc BID) or a sodium gluconate placebo, prior to their surveillance endoscopy procedure. Biopsies of Barrett's mucosa were then obtained for miRNA and mRNA microarrays, or protein analyses.

Results Zinc-induced mRNA changes were observed for a large number of transcripts. These included downregulation of transcripts encoding proinflammatory proteins (IL32, IL1 $\beta$, IL15, IL7R, IL2R, IL15R, IL3R), upregulation of anti-inflammatory mediators (IL1RA), downregulation of transcripts mediating epithelial-to-mesenchymal transition (EMT) (LIF, MYB, LYN, MTA1, SRC, SNAIL1, and TWIST1), and upregulation of transcripts that oppose EMT (BMP7, MTSS1, TRIB3, GRHL1). miRNA arrays showed significant upregulation of seven miRs with tumor suppressor activity (-125b-5P, -132-3P, $-548 z,-551 a,-504,-518$, and $-34 a-5 P)$. Of proteins analyzed by Western blot, increased expression of the pro-apoptotic protein, BAX, and the tight junctional protein, CLAUDIN-7, along with decreased expression of BCL-2 and VEGF-R2 were noteworthy.

Conclusions When these mRNA, miRNA, and protein molecular data are considered collectively, a cancer chemopreventive action by zinc in Barrett's metaplasia may be possible for this precancerous esophageal tissue. These results and the extensive prior animal model studies argue for a future prospective clinical trial for this safe, easily-administered, and inexpensive micronutrient, that could determine if a chemopreventive action truly exists.
\end{abstract}

Keywords Esophageal adenocarcinoma $\cdot$ Inflammation $\cdot$ Epithelial-to-mesenchymal transition $\cdot$ Chemoprevention $\cdot$ microRNA · Claudin

Electronic supplementary material The online version of this article (https://doi.org/10.1007/s10620-020-06319-x) contains supplementary material, which is available to authorized users.

J. M. Mullin

mullinj@mlhs.org

1 The Division of Gastroenterology, Lankenau Medical Center, Wynnewood, USA

2 The Department of Pathology, Lankenau Medical Center, Wynnewood, USA

3 The Lankenau Institute for Medical Research, 100 Lancaster Avenue, Wynnewood, PA 19096, USA
4 The Wistar Institute, Philadelphia, PA, USA

5 Department of Pathology, Anatomy, and Cell Biology, Thomas Jefferson University, Philadelphia, PA, USA

6 Sidney Kimmel Cancer Center, Thomas Jefferson University, Philadelphia, PA, USA 


\section{Introduction}

Due in part to the very low 5-year survival rate after diagnosis (and even after esophagectomy), esophageal adenocarcinoma (EAC) is viewed as one of the most severe cancer diagnoses. In the USA, the five-year survival rate for patients diagnosed with esophageal cancer across all stages is only $19.2 \%$; while the annual death rate has decreased between 2006 and 2015, it has done so by less than $1 \%$ per year [1]. EAC is the predominant histologic subtype of esophageal cancer in Western countries, and there has been a steadily increased incidence in EAC since the early 1970s. Identified risk factors for EAC include gastroesophageal reflux (GERD), obesity, tobacco use, and Barrett's esophagus (BE). BE is a precursor clinical condition to EAC that is characterized by metaplastic changes in the esophagus, specifically the formation of an intestinallike, secretory, columnar epithelium in an otherwise stratified squamous epithelial tissue [2]. BE is associated with factors including GERD, older age, obesity, smoking, and male gender. A case-control study found the odds ratio of developing EAC with weekly GERD symptoms to be $7.7 \%$, compared to individuals without GERD symptoms $[3,4]$. Currently, the prevalence of GERD in the USA is estimated around $20 \%$ of the population, with an increase in disease prevalence since 1995 [5]. The prevalence of $\mathrm{BE}$ in patients with symptomatic GERD is estimated to be 5-15\% [6]. This constitutes an enormous pool of people at risk for EAC. Although GERD typically presents with readily discernible symptoms, BE does not present with any symptoms that would distinguish it from its GERD precursor, and an endoscopic examination with biopsies is necessary for its discovery [3]. This stealth aspect makes the condition even more concerning.

Proton pump inhibitors (PPIs) directly inhibit gastric acid secretion by inhibiting the H,K-ATPase of the parietal cells of the stomach, reliably raising intragastric $\mathrm{pH}$ above a pH of 4 [7]. However, PPI drugs are not doing anything to directly act chemopreventively on Barrett's epithelia regarding the potential neoplastic progression of Barrett's, other than reducing further acid erosion of esophageal mucosa. PPI usage in patients with BE has been associated with a lower risk of EAC, but this may only be due to an indirect action [8]. Recent meta-analysis has in fact suggested that PPIs are not inhibiting EAC development in BE [9]. Aside from endoscopic surveillance of their Barrett's metaplasia for possible emergence of dysplasia or adenocarcinoma, BE patients have limited options for taking proactive steps to inhibit neoplastic progression of their condition.

The anticancer action of zinc has been known for over 40 years. Zinc suppression of sarcoma growth and L1210 leukemia cell growth in mice has been known since the 1970s [10, 11]. The subject of zinc deficiency correlating with various cancers as well as zinc supplementation serving as a possible chemopreventive agent in cancer has been recently and extensively reviewed $[12,13]$. Inhibition by zinc of esophageal cancer (squamous cell carcinoma [SCC]) development in mice dosed with the chemical carcinogen, $\mathrm{N}$-nitrosomethylbenzylamine, was reported over 30 years ago [14]. Inhibition by zinc of oral cancer in mice had been observed by Poswillo [15]. Moreover, zinc was reported to inhibit cancer cell growth at concentrations not affecting normal cell growth [16]. Zinc has been twice shown to inhibit dimethylhydrazine-induced colon carcinogenesis in mice and rats including not only effects on tumor burden but on preneoplastic tissue changes as well [17-19]. The inverse correlation of zinc tissue levels with prostate cancer has been observed, as was an inhibitory effect of zinc supplementation on chemically induced prostate cancer in rodents [20, 21]. However, the science is not universally in agreement on zinc's anticancer action as zinc gluconate was reported to be ineffective against dimethylhydrazine-induced colon carcinogenesis in rodents [22].

The most compelling evidence that zinc may be chemopreventive for esophageal squamous cell cancer (SCC) in humans comes out of the large body of work on rodent models by the research laboratory of LY Fong. Work from this group has clearly shown promotion of esophageal cancer (SCC) by zinc deficiency [23, 24]. But there is also clear evidence that zinc supplementation is chemopreventive in these animals for induction of SCC of the esophagus, tongue, and oral cavity $[11,25,26]$.

It is true that all of the rodent model esophageal cancer findings previously reported for zinc deal exclusively with SCC, whereas Barrett's epithelia develop into EAC, a totally different neoplastic lineage [11, 23, 24]. Therefore, one could not be assured that zinc would have similar cancer-preventive action regarding neoplastic progression coming from Barrett's metaplasia, as it does with development of SCC. However, a large body of nutritional and dietary studies have been published over time that show associations among zinc deficiency, zinc supplementation, and esophageal cancers in general [27]. Our current study was designed to specifically address that question, as well as being the first study in humans to address zinc's esophageal cancer preventive action. A study in humans was deemed worthwhile because of the known difficulty of achieving adequate animal models for the condition of BE [28]. Issues surrounding the completely accurate reflection of various animal models for Barrett's metaplasia in humans ([29]) plus the issue of the wellknown safety of the therapeutic intervention here- $26 \mathrm{mg}$ zinc gluconate BID-induced us to initiate this pilot study in humans. We sought to observe if the chemopreventive action 
reported for zinc-inhibiting SCC in rodents could extend to the Barrett's-driven EAC risk in humans.

This current study does not contribute fundamentally to the mechanism of zinc's potentially chemopreventive role in cancer other than to show changes in cellular signaling and other molecular intermediates as a result of zinc treatment. We would point out however that there are three actions of zinc that have a high probability of figuring prominently in zinc's effects on neoplasia. The first is that zinc has welldescribed antioxidant activity, both acutely and chronically ([30-32]). The second is that zinc binds to and regulates various isoforms of the Protein Kinase $\mathrm{C}$ family of signaling proteins, proteins that are highly involved in the tumor promotional phase of carcinogenesis ([33]). The third is that zinc has been reported to stabilize full length APC protein and thereby promote apoptotic activity ([34]).

\section{Methods and Materials}

\section{Patient Demographics and Enrollment}

This research study was reviewed and approved by the Lankenau Medical Center Institutional Review Board. All enrolled subjects provided written informed consent. Previously identified BE patients in the Lankenau Medical Center, Division of Gastroenterology patient practice, were contacted for recruitment $6-8$ weeks prior to their regularly scheduled endoscopic surveillance procedure. Prior diagnosis of BE in all enrolled test subjects was made by a staff pathologist on the basis of identification of goblet cell metaplasia in hematoxylin/eosin-stained sections of suspected Barrett's tissue biopsies. Criteria for enrollment exclusion were insulin-dependent diabetes, prior history of Barrett's dysplasia or neoplasia, and the following medications: amiloride-class diuretics, fluoroquinolone antibiotics, anticoagulants (except for aspirin), hormone-replacement therapy, and cholestyramine; these being medications which could be interfered with by supplemental zinc. Demographic characteristics of the Barrett's patients enrolled in this study are shown in Table 1. Approximately $75 \%$ of Barrett's patients that were approached to participate in this study, agreed to participate and provided written informed consent.

\section{Zinc Medication}

Zinc was administered in lozenge form to prolong the contact time of the administered zinc with the esophageal mucosa. Patients were instructed to take two zinc lozenges each morning and evening for 14 days prior to their upper endoscopy procedure. Each lozenge contained $13.2 \mathrm{mg}$ of zinc in the form of zinc gluconate with other inert ingredients, for a total daily supplemental zinc intake of $52.8 \mathrm{mg}$. Patients
Table 1 Patient demographics relating to biopsy tissue samples used in mRNA, miRNA, and protein analyses

\begin{tabular}{|c|c|c|c|c|}
\hline & \multicolumn{2}{|c|}{ Placebo group } & \multicolumn{2}{|c|}{$\begin{array}{l}\text { Zinc supplement } \\
\text { group }\end{array}$} \\
\hline & $n$ & $\%$ of total & $n$ & $\%$ of tota \\
\hline \multicolumn{5}{|l|}{ mRNA study } \\
\hline \multicolumn{5}{|l|}{ Age } \\
\hline $40-49$ & 2 & 40.0 & 0 & 0.0 \\
\hline $50-59$ & 1 & 20.0 & 2 & 40.0 \\
\hline $60-69$ & 2 & 40.0 & 1 & 20.0 \\
\hline $70+$ & 0 & 0.0 & 2 & 40.0 \\
\hline \multicolumn{5}{|l|}{ Gender } \\
\hline Female & 2 & 40.0 & 3 & 60.0 \\
\hline Male & 3 & 60.0 & 2 & 40.0 \\
\hline \multicolumn{5}{|l|}{ Ethnicity } \\
\hline Caucasian & 4 & 80.0 & 5 & 100.0 \\
\hline African American & 0 & 0.0 & 0 & 0.0 \\
\hline Hispanic & 1 & 20.0 & 0 & 0.0 \\
\hline Asian & 0 & 0.0 & 0 & 0.0 \\
\hline \multicolumn{5}{|c|}{ Barrett's segment length } \\
\hline $1 \mathrm{~cm}$ & 1 & 20.0 & 2 & 40.0 \\
\hline $2 \mathrm{~cm}$ & 4 & 80.0 & 2 & 40.0 \\
\hline $3 \mathrm{~cm}$ & 0 & 0.0 & 0 & 0.0 \\
\hline$>3 \mathrm{~cm}$ & 0 & 0.0 & 1 & 20.0 \\
\hline \multicolumn{5}{|c|}{ Proton pump inhibitor use } \\
\hline Omeprazole & 2 & 40.0 & 4 & 80.0 \\
\hline Esomeprazole & 0 & 0.0 & 1 & 20.0 \\
\hline Pantoprazole & 2 & 40.0 & 0 & 0.0 \\
\hline Lansoprazole & 1 & 20.0 & 0 & 0.0 \\
\hline Dexlansoprazole & 0 & 0.0 & 0 & 0.0 \\
\hline \multicolumn{5}{|l|}{ miRNA study } \\
\hline \multicolumn{5}{|l|}{ Age } \\
\hline $40-49$ & 2 & 33.3 & 0 & 0.0 \\
\hline $50-59$ & 1 & 16.7 & 0 & 0.0 \\
\hline $60-69$ & 3 & 50.0 & 5 & 83.3 \\
\hline $70+$ & 0 & 0.0 & 1 & 16.7 \\
\hline \multicolumn{5}{|l|}{ Gender } \\
\hline Female & 2 & 33.3 & 4 & 66.7 \\
\hline Male & 4 & 66.7 & 2 & 33.3 \\
\hline \multicolumn{5}{|l|}{ Ethnicity } \\
\hline Caucasian & 4 & 66.7 & 6 & 100.0 \\
\hline African American & 1 & 16.7 & 0 & 0.0 \\
\hline Hispanic & 1 & 16.7 & 0 & 0.0 \\
\hline Asian & 0 & 0.0 & 0 & 0.0 \\
\hline \multicolumn{5}{|c|}{ Barrett's segment length } \\
\hline $1 \mathrm{~cm}$ & 2 & 33.3 & 1 & 16.7 \\
\hline $2 \mathrm{~cm}$ & 3 & 50.0 & 3 & 50.0 \\
\hline $3 \mathrm{~cm}$ & 0 & 0.0 & 1 & 16.7 \\
\hline$>3 \mathrm{~cm}$ & 1 & 16.7 & 1 & 16.7 \\
\hline \multicolumn{5}{|c|}{ Proton pump inhibitor use } \\
\hline Omeprazole & 3 & 50.0 & 4 & 66.7 \\
\hline Esomeprazole & 1 & 16.7 & 1 & 16.7 \\
\hline
\end{tabular}


Table 1 (continued)

\begin{tabular}{|c|c|c|c|c|}
\hline & \multicolumn{2}{|c|}{ Placebo group } & \multicolumn{2}{|c|}{$\begin{array}{l}\text { Zinc supplement } \\
\text { group }\end{array}$} \\
\hline & $n$ & $\%$ of total & $n$ & $\%$ of total \\
\hline Pantoprazole & 1 & 16.7 & 0 & 0.0 \\
\hline Lansoprazole & 1 & 16.7 & 1 & 16.7 \\
\hline \multicolumn{5}{|l|}{ Protein study: $B A X$} \\
\hline \multicolumn{5}{|l|}{ Age } \\
\hline $40-49$ & 0 & 25.0 & 1 & 25.0 \\
\hline $50-59$ & 1 & 0.0 & 1 & 25.0 \\
\hline $60-69$ & 2 & 25.0 & 0 & 25.0 \\
\hline $70+$ & 1 & 50.0 & 2 & 25.0 \\
\hline \multicolumn{5}{|l|}{ Gender } \\
\hline Female & 2 & 50.0 & 0 & 50.0 \\
\hline Male & 2 & 50.0 & 4 & 50.0 \\
\hline \multicolumn{5}{|l|}{ Ethnicity } \\
\hline Caucasian & 4 & 100.0 & 4 & 100.0 \\
\hline African American & 0 & 0.0 & 0 & 0.0 \\
\hline Hispanic & 0 & 0.0 & 0 & 0.0 \\
\hline Asian & 0 & 0.0 & 0 & 0.0 \\
\hline \multicolumn{5}{|c|}{ Barrett's segment length } \\
\hline $1 \mathrm{~cm}$ & 2 & 75.0 & 0 & 75.0 \\
\hline $2 \mathrm{~cm}$ & 2 & 0.0 & 1 & 25.0 \\
\hline $3 \mathrm{~cm}$ & 0 & 0.0 & 0 & 0.0 \\
\hline$>3 \mathrm{~cm}$ & 0 & 25.0 & 3 & 0.0 \\
\hline \multicolumn{5}{|c|}{ Proton pump inhibitor use $\mathrm{e}^{* *}$} \\
\hline Omeprazole & 1 & 50.0 & 1 & 33.3 \\
\hline Esomeprazole & 0 & 0.0 & 2 & 33.3 \\
\hline Pantoprazole & 2 & 50.0 & 0 & 0.0 \\
\hline Lansoprazole & 0 & 0.0 & 1 & 33.3 \\
\hline \multicolumn{5}{|l|}{ Protein study: claudin } \\
\hline \multicolumn{5}{|l|}{ Age } \\
\hline $40-49$ & 1 & 25.0 & 1 & 25.0 \\
\hline $50-59$ & 0 & 0.0 & 1 & 25.0 \\
\hline $60-69$ & 1 & 25.0 & 1 & 25.0 \\
\hline $70+$ & 2 & 50.0 & 1 & 25.0 \\
\hline \multicolumn{5}{|l|}{ Gender } \\
\hline Female & 2 & 50.0 & 2 & 50.0 \\
\hline Male & 2 & 50.0 & 2 & 50.0 \\
\hline \multicolumn{5}{|l|}{ Ethnicity } \\
\hline Caucasian & 4 & 100.0 & 4 & 100.0 \\
\hline African American & 0 & 0.0 & 0 & 0.0 \\
\hline Hispanic & 0 & 0.0 & 0 & 0.0 \\
\hline Asian & 0 & 0.0 & 0 & 0.0 \\
\hline \multicolumn{5}{|c|}{ Barrett's segment length } \\
\hline $1 \mathrm{~cm}$ & 3 & 75.0 & 3 & 75.0 \\
\hline $2 \mathrm{~cm}$ & 0 & 0.0 & 1 & 25.0 \\
\hline $3 \mathrm{~cm}$ & 0 & 0.0 & 0 & 0.0 \\
\hline$>3 \mathrm{~cm}$ & 1 & 25.0 & 0 & 0.0 \\
\hline \multicolumn{5}{|c|}{ Proton pump inhibitor use } \\
\hline Omeprazole & 2 & 50.0 & 2 & 50.0 \\
\hline
\end{tabular}

Table 1 (continued)

\begin{tabular}{|c|c|c|c|c|}
\hline & \multicolumn{2}{|c|}{ Placebo group } & \multicolumn{2}{|c|}{$\begin{array}{l}\text { Zinc supplement } \\
\text { group }\end{array}$} \\
\hline & $n$ & $\%$ of total & $n$ & $\%$ of total \\
\hline Esomeprazole & 0 & 0.0 & 1 & 25.0 \\
\hline Pantoprazole & 2 & 50.0 & 0 & 0.0 \\
\hline Lansoprazole & 0 & 0.0 & 1 & 25.0 \\
\hline
\end{tabular}

**1 patient in the placebo group was not taking any PPI medication

were instructed to take the two lozenges consecutively, not simultaneously, to not chew the lozenges or swallow them whole, and to refrain from foods containing phytates or citrus for $1 \mathrm{~h}$ before or after the lozenges; these foods being known to reduce cellular zinc uptake by rendering zinc nonabsorbable. A parallel, placebo group of Barrett's patients received lozenges containing a molar equivalent amount of sodium gluconate. Patients were randomly assigned to the zinc or placebo subgroups by the sealed envelope method. Study patients were blinded as to which treatment group that they were enrolled (placebo or zinc) until they completed the study and provided biopsy tissue.

Normal (dietary) zinc intake is considered in the range of 5-10 mg/adult/day, and toxic limits are generally viewed to be above $150 \mathrm{mg} /$ adult/day. Lower doses $(<100 \mathrm{mg} /$ adult/ day) have generally been considered safe and without effect on systemic copper levels $[35,36]$. Hundred milligrams of zinc/adult/day had no significant effect on plasma copper levels over 3 months in an elderly population [37]. Zinc levels in excess of $150 \mathrm{mg} /$ adult/day were required to cause changes in copper status, immune function, and HDL levels [38].

The transit time/turnover time of epithelial mucosa for normal stratified squamous esophagus is 7.5 days, whereas intestine is only 3 days ([39]). If Barrett's is similar to either of these-and results on Ki67 and IdU labeling of Barrett's cells suggest that it is slower but still less than 14 days ([40]) —our 14-day treatment time allows for at least one refoliation of the tissue in the presence of zinc. Therefore, we are allowing for not only zinc effects on existing, differentiated Barrett's epithelia, but also zinc effects on undifferentiated epithelia (and stem cells) in the crypt regions of the Barrett's metaplasia. Not knowing what population of Barrett's epithelia would be the most amenable to zinc action, a 14-day treatment allows us to cover both possibilities.

Our research group has published on the ability of zinc to favorably remodel the tight junctional complexes of various human epithelial cell culture models ([41-45]. This involved zinc-induced upregulations and downregulations of various claudin proteins that resulted in junctional seals that are less leaky. The optimal concentration range to achieve this effect was $50-100 \mu \mathrm{M}$. If one administers a twice daily dose of 
$26.6 \mathrm{mg}$ zinc and this results in total absorption into the bloodstream followed by dilution across a $5 \mathrm{~L}$ blood volume, one is in the middle of this range, twice daily. That was the rationale for the administered dosage. This is however vastly over simplistic as it ignores confounding factors such as transport of zinc into cellular spaces, binding of zinc to metallothioneins, elimination of zinc by the kidney, etc. In addition, it ignores the specific method of zinc delivery used here-a slow dissolving lozenge which results in coating of the oral cavity and esophageal mucosa, in essence a topical delivery of zinc to the (apical surface of the) Barrett's target tissue. It was previously documented by our group that this oral dosage with this mode of administration (orally administered lozenges) achieved a pharmacologically effective dose in the Barrett's cells ([46]).

\section{Esophageal Biopsy Collection}

During the patient's endoscopic exam, diagnostic biopsies were taken in four quadrants at one centimeter intervals with standard biopsy forceps for histological evaluation. Four additional standard biopsy samples $(1 \mathrm{~mm})$ were then taken from the apparent Barrett's region for research purposes and flash-frozen on dry ice in the endoscopy procedures room for later RNA microarray or protein chemistry analyses as described below. The four biopsies were pooled in order to yield enough material for RNA or protein assay.

Different groups of patients have been used in the different studies reported here (miRNA, mRNA, etc.) because of the limiting amount of tissue (biopsies) taken from each patient. For both protein and RNA analyses, we found it necessary to pool 4 standard biopsies (1 mm each) from a given tissue region in order to have sufficient cell material to extract enough protein or RNA to then conduct the required analyses. Taking more biopsies (from each patient) would have lengthened the patient's anesthesia exposure time, but also reduced the confidence of biopsy accuracy. This is because the transient mucosal bleeding that begins upon taking the initial biopsy can obscure the tissue field and reduce confidence in obtaining biopsies from specific regions (e.g., Barrett's metaplasia vs normal squamous esophagus).

\section{mRNA RNA-seq Analyses}

For RNA-seq analysis, RNA was extracted from Barrett's metaplasia tissue biopsies by Trizol (Invitrogen) and subsequently cleaned and DNase-treated using RNeasy columns (Qiagen). 3' mRNA-seq libraries were generated from DNase-treated total RNA using the QuantSeq FWD library preparation kit (Lexogen) according to the manufacturer's directions. Overall, library size was determined using the Agilent Tapestation and the DNA 5000 Screentape (Agilent). Libraries were quantified using real-time
PCR (KapaBiosystems). Libraries were pooled, and highoutput single-read 75-base-pair next-generation sequencing was done on a NextSeq 500 (Illumina). RNA-seq data were aligned using Bowtie2 [47] against hg 19 version of the human genome, and RSEM version 1.2.12 software [48] was used to estimate raw read counts for each gene using Ensemble v84 transcriptome information. DESeq 2 [49] was used to estimate the significance of the differential expression between sample groups.

\section{miRNA Microarray Analyses}

Human miRNA expression assay (nanoString nCounter system) that detects $>800$ human miRNA $[50,51]$ was used for miRNA expression profiling in esophagus biopsies. This assay was performed at the Ohio State University Comprehensive Cancer Center Nucleic Acid Facility. Total RNA (100 ng) was used as input material. Small RNA samples were prepared by ligating a specific DNA tag onto the $3^{\prime}$ end of each mature miRNA according to manufacturer's instruction (nanoString Technologies). These tags normalized the melting temperatures $\left(T_{\mathrm{m}} \mathrm{s}\right)$ of the miRNAs and provided identification for each miRNA species in the sample. Excess tags were then removed, and the resulting material was hybridized with a panel of miRNA:tag-specific nCounter capture and barcoded reporter probes. Hybridization reactions were incubated at $64{ }^{\circ} \mathrm{C}$ for $18 \mathrm{~h}$. Hybridized probes were purified and immobilized on a streptavidin-coated cartridge using the nCounter Prep Station (nanoString Technologies). nCounter digital analyzer was used to count individual fluorescent barcodes and quantify target RNA molecules present in each sample. For each assay, a high-density scan (600 fields of view) was performed. Abundances of miRNAs were quantified using the nanoString nCounter gene expression system [52]. Each sample was normalized to the geometric mean of the top 50 most highly expressed miRNAs. Student's $t$ test was used to calculate statistical significances of pairwise comparisons.

\section{Western Blot Analyses}

Biopsies of Barrett's mucosa were collected in the endoscopy unit as described above and then flash-frozen on dry ice and stored at $-80{ }^{\circ} \mathrm{C}$ until homogenization. Tissue was thawed and resuspended in lysis buffer containing sodium dodecyl sulfate with protease and phosphatase inhibitors and then homogenized by hand using glass mortars/pestles (Wheaton), thereby generating a total cell lysate. Suspensions were then sonicated, extracted for 75-90 min at $4{ }^{\circ} \mathrm{C}$ on a rotator, and ultracentrifuged. Cellular proteins were separated on Novex tris-glycine minigels. Primary antibodies to the proteins BAX, BCL-2, and CLAUDIN-7 were products of Cell Signaling Technology, Inc. (Danvers, 
MA). Primary antibodies to the protein VEGF-R2 were a product of Thermo Fisher (Waltham, MA). Secondary antibodies were purchased from Southern Biotech (Birmingham, $A L)$. Quantification of Western blot results was performed by densitometry of specific protein bands using a Bio-Rad Chemidoc MP Imaging System. Densitometry conducted on Memcode stains of total protein served as loading controls for all Western blot data shown [53].

\section{Statistics}

The Student's $t$ test was used to calculate statistical significance $(P<0.05$, two-tailed or one-tailed as indicated) for pairwise comparisons (placebo treatment group vs zinc treatment group). NS: not significant $(P>0.05)$.

\section{Results}

\section{Patient Demographics}

The demographic data for the patients whose Barrett's tissue was analyzed are shown in Table 1. All patients enrolled in the study were on long-term, continuous PPI therapy, the most common being omeprazole. As anticipated from the published literature involving $\mathrm{BE}$, most patients were Caucasian and the majority were males over 50 years of age. Barrett's segment length varied considerably.

The study excluded any patients who were currently taking insulin, fluoroquinolone antibiotics, or amiloride-class diuretics, due to potential interactions that zinc could have with these medications' uptake or actions. Patients with any history of Barrett's dysplasia were also excluded, as well as patients who had prior esophageal surgery or any endoscopic interventions such as radiofrequency ablation or endoscopic mucosal resection to their Barrett's tissue.

Patients on a strict vegan diet were excluded due to the likelihood of lower-than-normal zinc intake from the absence of meat, fish, or dairy in their diet. We recorded whether any patients were on a daily nutritional zinc supplement greater than $10 \mathrm{mg}$ of zinc/day.

\section{mRNA RNA-seq}

As described in Methods section, RNA was isolated from Barrett's tissue biopsy samples from 5 zinc-treated and 5 placebo-treated BE patients, whose demographic characteristics are given in Table 1 and assayed using RNA-seq. Of the over 27,000 detected genes, we observed significant changes in 2773 genes $(P<0.05)$ (Supplemental File). 1314 gene transcripts upregulated and 1459 downregulated in zinc-treated patients. The heatmap shown in Fig. 1 demonstrates a small subset of those genes with at least 1.5-fold induced changes and whose change was consistent with a potentially cancer chemopreventive action by zinc, based upon evidence from the published literature.

Among these zinc-induced transcript changes, two general themes were observed. First, many of the zinc-induced changes formed an anti-inflammatory pattern. These changes-both downregulations and upregulations-are highlighted in yellow in Fig. 1a and B. Included among these are downregulations (Fig. 1a) of the interleukin-2 receptor (IL2RB) (2.7 fold), the interleukin-3 receptor (IL3RA) (threefold), the interleukin-17 receptor (IL17RB) (3.3-fold), the interferon gamma receptor (IFNGR1) (2.3-fold), and the interleukin-7 receptor (IL7R) (2.6-fold). Specific proinflammatory cytokines were significantly downregulated as well: interleukin-32 (IL32) (4.5-fold), interleukin-15 (IL15) (2.3-fold), and interleukin-1-beta (IL1B) (2.2-fold). There were also significant upregulations (Fig. 1b) that would be consistent with an anti-inflammatory profile, such as the interleukin 1 receptor antagonist (IL1RN) (3.9-fold) and the interleukin 36 receptor antagonist (IL36RN) (7.2-fold).

The second cancer preventive theme that could be observed in the zinc treatment group was a broad-based downregulation (Fig. 1a) of mediators of epithelial-to-mesenchymal transition (EMT), the general cellular dedifferentiation program that appears to accompany neoplastic progression. There were also upregulations (Fig. 1b) of transcripts with an anti-EMT role. These changes are highlighted in green in Fig. 1. These included statistically significant downregulations of leukemia inhibitory factor (LIF) (6.3-fold), v-myb myeloblastosis viral oncogene homolog (MYB) (3.6fold), v-yes-1 Yamaguchi sarcoma viral related oncogene homolog (LYN) (2.0-fold), metastasis associated 1 (MTA1) (1.7-fold), Indian Hedgehog (IHH) (1.7-fold), and v-src Sarcoma viral oncogene homolog (SRC) (1.6-fold). Snail family zinc finger 1 (SNAI1) (2.6-fold) and twist basic helixloop-helix transcription factor (TWIST1) (2.2-fold) were each downregulated over twofold but failed to quite achieve statistical significance $(P<0.1)$. Zinc-induced upregulations of genes with an anti-EMT profile included bone morphogenetic protein 7 (BMP7) (2.1-fold), secreted frizzled-related protein 1 (SFRP1) (3.2-fold), grainy head-like 1 (GRHL1) (4.8-fold), and metastasis suppressor 1 (MTSS1) (2.2-fold). The Discussion section provides references for the anticancer activity attributed to all of these various genes.

There were many other transcriptional changes-both up- and downregulations - that individually suggested anticancer effects of zinc on specific miscellaneous proteins with known causal roles in the neoplastic process. Among these are significant downregulations (Fig. 1a) of matrix metallopeptidase 12 (MMP12) (8.5-fold), prostaglandin E receptor 4 (PTGER4) (2.2-fold), MAP kinase kinase 3 (MAP2K3) (1.7-fold), protein kinase C-alpha (PRKCA) (1.6-fold), and 
Fig. 1 Heatmap showing a sampling of genes whose expression was significantly altered by zinc treatment and which have documented associations or roles in $\mathrm{BE}$ progression to neoplasia. Gene expression data are shown for 5 placebo-treated patients $(P)$ and 5 zinc-treated patients $(Z)$. a Genes downregulated as a result of zinc treatment; $\mathbf{b}$ genes upregulated as a result of zinc treatment. Data include average fold-change in the mRNA transcript level and the $\mathrm{P}$ value for the statistical confidence. One of the placebo patients (P5) showed characteristics of the zinc treatment group for reasons unknown. Genes whose up- or downregulation evidences an anti-inflammatory action of zinc treatment are highlighted in yellow. Genes whose up- or downregulation suggests zincinduced inhibition of epithelialto-mesenchymal transition (EMT) signaling are highlighted in green (a)

\begin{tabular}{|c|c|c|c|c|c|c|c|c|c|}
\hline fold & pvalue & & & & & 3 & & Gene & Description \\
\hline-179 & 4E-06 & & & & & & & CA1 & carbonic anhydrase I \\
\hline-134 & 0.02 & & & & & & & PLA2G12B & phospholipase A2, group XIIB \\
\hline-90.5 & $1 \mathrm{E}-08$ & & & & & & & ANPEP & alanyl (membrane) aminopeptidase \\
\hline-84.4 & 6E-06 & & & & & & & KLK3 & kallikrein-related peptidase 3 \\
\hline-77.8 & 6E-05 & & & & & & & CA7 & carbonic anhydrase VII \\
\hline-57.8 & $3 E-04$ & & & & & & & NOX1 & NADPH oxidase 1 \\
\hline-56.9 & 0.004 & & & & & & & sı & sucrase-isomaltase (alpha-glucosidase) \\
\hline-34.5 & 4E-04 & & & & & & & Muc2 & mucin 2, oligomeric mucus/gel-forming \\
\hline-26.9 & 0.004 & & & & & & & KLK15 & kallikrein-related peptidase 15 \\
\hline-20.6 & $2 \mathrm{E}-06$ & & & & & & & $\operatorname{cox} 2$ & caudal type homeobox 2 \\
\hline-13.4 & $7 E-04$ & & & & & & & CLDN3 & claudin 3 \\
\hline-8.55 & 5E-09 & & & & & & & MMP12 & matrix metallopeptidase 12 (macrophage elastase) \\
\hline-8.50 & 0.006 & & & & & & & REG4 & regenerating islet-derived family, member 4 \\
\hline-6.36 & $9 \mathrm{E}-11$ & & & & & & & Muc13 & mucin 13, cell surface associated \\
\hline-6.35 & 0.011 & & & & & & & LIF & leukemia inhibitory factor \\
\hline-5.46 & 2E-06 & & & & & & & HEPH & hephaestin \\
\hline-4.81 & $4 \mathrm{E}-04$ & & & & & & & KLK1 & kallikrein 1 \\
\hline-4.49 & $2 E-07$ & & & & & & & IL32 & interleukin 32 \\
\hline-3.96 & $1 \mathrm{E}-08$ & & & & & & & EPCAM & epithelial cell adhesion molecule \\
\hline-3.91 & $2 \mathrm{E}-04$ & & & & & & & CYBRD1 & cytochrome b reductase 1 \\
\hline-3.61 & $7 E-04$ & & & & & & & MYB & v-myb myeloblastosis viral oncogene homolog (avian) \\
\hline-3.44 & $8 \mathrm{E}-05$ & & & & & & & SOD3 & superoxide dismutase 3, extracellular \\
\hline-3.34 & 0.026 & & & & & & & IL17RB & interleukin 17 receptor $B$ \\
\hline-3.24 & $4 \mathrm{E}-05$ & & & & & & & CLDN4 & claudin 4 \\
\hline-3.13 & 0.002 & & & & & & & IRAK2 & interleukin-1 receptor-associated kinase 2 \\
\hline-3.00 & 0.004 & & & & & & & IL3RA & interleukin 3 receptor, alpha (low affinity) \\
\hline-2.97 & $4 E-05$ & & & & & & & TNFRSF11A & tumor necrosis factor receptor superfamily, member 11a \\
\hline-2.97 & $2 E-04$ & & & & & & & CES 3 & carboxylesterase 3 \\
\hline-2.92 & $5 E-05$ & & & & & & & CLDN7 & claudin 7 \\
\hline-2.90 & $1 \mathrm{E}-04$ & & & & & & & CD55 & CD55 molecule, decay accelerating factor for complement \\
\hline-2.86 & $1 \mathrm{E}-04$ & & & & & & & socs 1 & suppressor of cytokine signaling 1 \\
\hline-2.84 & 0.001 & & & & & & & ACE & angiotensin I converting enzyme (peptidyl-dipeptidase A) 1 \\
\hline-2.70 & 0.008 & & & & & & & IL2RB & interleukin 2 receptor, beta \\
\hline-2.63 & 0.003 & & & & & & & IL7R & interleukin 7 receptor \\
\hline-2.59 & 0.09 & & & & & & & SNAI1 & snail family zinc finger 1 \\
\hline-2.51 & 0.014 & & & & & & & IL15RA & interleukin 15 receptor, alpha \\
\hline-2.35 & 0.008 & & & & & & & TNFRSF12A & tumor necrosis factor receptor superfamily, member $12 \mathrm{~A}$ \\
\hline-2.35 & 0.008 & & & & & & & IL15 & interleukin 15 \\
\hline-2.26 & 0.041 & & & & & & & TRAF1 & TNF receptor-associated factor 1 \\
\hline-2.26 & $7 E-05$ & & & & & & & IFNGR1 & interferon gamma receptor 1 \\
\hline-2.24 & 0.071 & & & & & & & TWIST1 & twist basic helix-loop-helix transcription factor 1 \\
\hline-2.20 & 0.043 & & & & & & & IL1B & interleukin 1, beta \\
\hline-2.18 & $4 E-05$ & & & & & & & PTGER4 & prostaglandin E receptor 4 (subtype EP4) \\
\hline-2.09 & 0.015 & & & & & & & SEPP1 & selenoprote in P, plasma, 1 \\
\hline-2.06 & 0.009 & & & & & & & TNFSF13B & tumor necrosis factor (ligand) superfamily, member 13b \\
\hline-2.00 & $3 \mathrm{E}-04$ & & & & & & & PLA2G16 & phospholipase A2, group XVI \\
\hline-1.96 & $7 E-04$ & & & & & & & CA13 & carbonic anhydrase XIII \\
\hline-1.96 & $2 E-05$ & & & & & & & LYN & v-yes-1 Yamaguchi sarcoma viral related oncogene homolog \\
\hline-1.95 & 0.006 & & & & & & & VDR & vitamin $D(1,25$ - dihydroxyvitamin $D 3)$ receptor \\
\hline-1.89 & 0.003 & & & & & & & PLCB3 & phospholipase $C$, beta 3 (phosphatidylinositol-specific) \\
\hline-1.87 & 0.002 & & & & & & & TNFRSF1B & tumor necrosis factor receptor superfamily, member $1 \mathrm{~B}$ \\
\hline-1.87 & $2 \mathrm{E}-04$ & & & & & & & стSC & cathepsin C \\
\hline-1.83 & 0.004 & & & & & & & SIRT6 & sirtuin 6 \\
\hline-1.82 & 0.069 & & & & & & & LTB & lymphotoxin beta (TNF superfamily, member 3 ) \\
\hline-1.82 & 0.015 & & & & & & & BORA & bora, aurora kinase $\mathrm{A}$ activator \\
\hline-1.79 & 0.001 & & & & & & & PROM1 & prominin 1 \\
\hline-1.79 & 0.016 & & & & & & & GDF15 & growth differentiation factor 15 \\
\hline-1.78 & 6E-04 & & & & & & & STATSA & signal transducer and activator of transcription 5A \\
\hline-1.73 & 0.032 & & & & & & & MTA1 & metastasis associated 1 \\
\hline-1.72 & 0.008 & & & & & & & TNFRSF1OB & tumor necrosis factor receptor superfamily, member $10 b$ \\
\hline-1.67 & 0.005 & & & & & & & MAP 2K3 & mitogen-activated protein kinase kinase 3 \\
\hline-1.67 & 0.037 & & & & & & & CTHRC1 & collagen triple helix repeat containing 1 \\
\hline-1.66 & 0.035 & & & & & & & IHH & indian hedgehog \\
\hline-1.66 & $3 E-04$ & & & & & & & ID2 & inhibitor of DNA binding 2 \\
\hline-1.65 & 0.006 & & & & & & & PLCD3 & phospholipase C, delta 3 \\
\hline-1.64 & 0.012 & & & & & & & CLDN12 & claudin 12 \\
\hline-1.64 & 0.004 & & & & & & & TNFRSF14 & tumor necrosis factor receptor superfamily, member 14 \\
\hline-1.62 & 0.003 & & & & & & & $\mathrm{CDH1}$ & cadherin 1, type 1, E-cadherin (epithelial) \\
\hline-1.60 & 0.001 & & & & & & & PRKCA & protein kinase $\mathrm{C}$, alpha \\
\hline-1.56 & 0.005 & & & & & & & SRC & $\mathrm{v}$-src sarcoma (Schmidt-Ruppin A-2) viral oncogene he \\
\hline-1.55 & 0.005 & & & & & & & CASP3 & caspase 3 , apoptosis-related cysteine peptidase \\
\hline-1.54 & 0.03 & & & & & & & MAP2K2 & mitogen-activated protein kinase kinase 2 \\
\hline-1.41 & 0.044 & & & & & & & MAP 2K5 & mitogen-activated protein kinase kinase 5 \\
\hline
\end{tabular}

(b)




1202

Digestive Diseases and Sciences (2021) 66:1195-1211
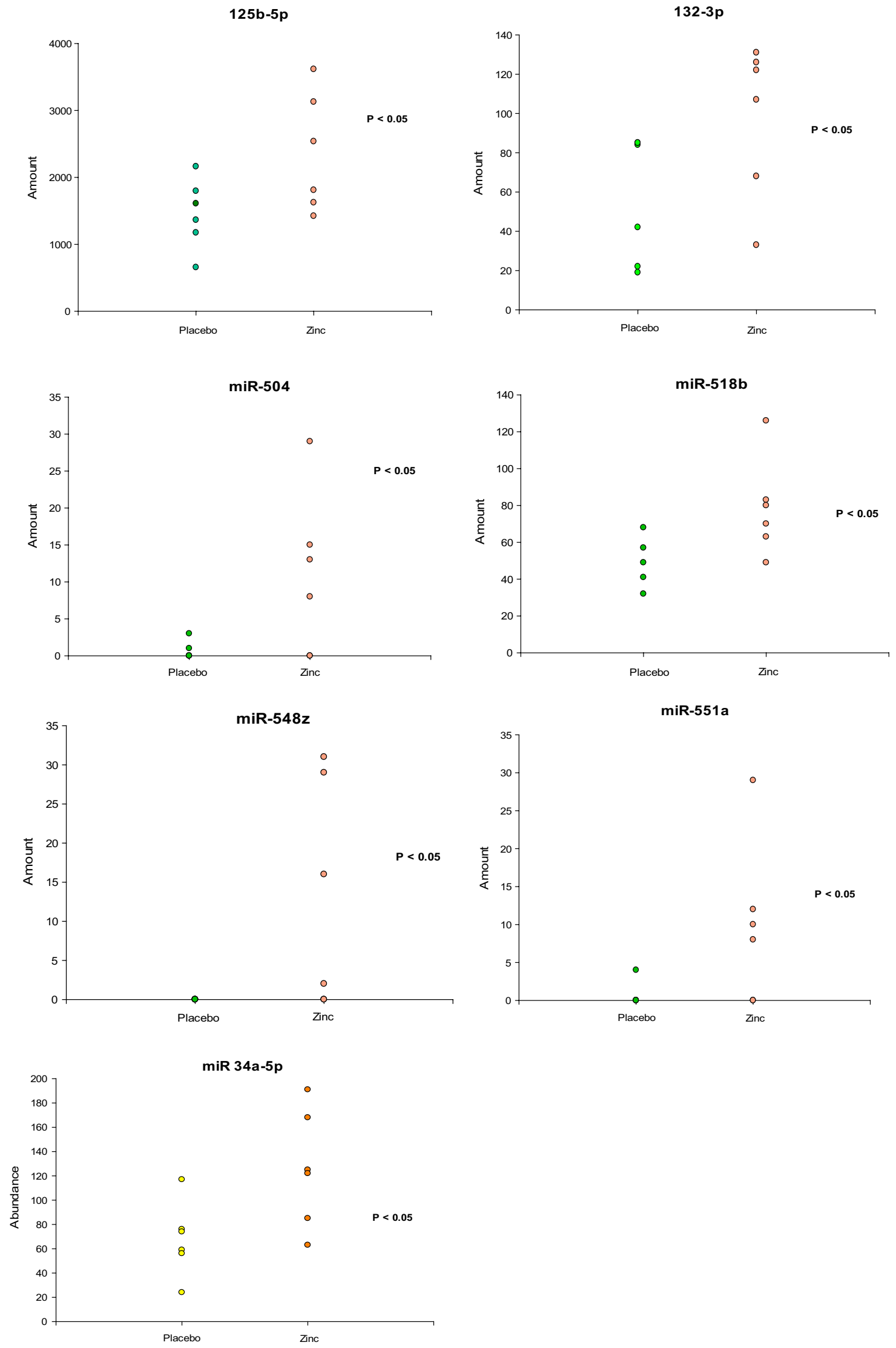

Springer 
४Fig. 2 Effect of zinc on miRNA species present in Barrett's epithelia. Seven miRNA species that were significantly upregulated in BE biopsy samples of the zinc treatment group $(P<0.05$, Student's $t$ test, one-tailed) are shown as vertical point plots. Each data point represents the miRNA abundance for a specific patient $(n=6$ zinc-treated patients and 6 placebo patients per miRNA analyzed). RNA purification and miRNA analyses are described in Methods

MAP kinase kinase kinase 5 (MAP3K5) (1.5-fold). General zinc-induced upregulation events (Fig. 1b) that may have an anticancer action here occurred as well, such as a 1.8-fold increase in the insulin-like growth factor 1 receptor (IGF1R).

There were many more numerous instances of zincinduced up- and downregulations of transcripts that are known to have strong associations - if not causal activitywith neoplastic progression of Barrett's epithelia. These would include zinc-induced downregulations of specific transcripts in this study that are reported to upregulate in the transition from Barrett's metaplasia to dysplasia or adenocarcinoma. Examples of this are significant downregulations of the tight junctional proteins, claudin-3 (CLDN3) (13.3fold), claudin-4 (CLDN4) (3.2-fold), claudin-7 (CLDN7) (2.9-fold), and claudin-12 (CLDN12) (1.6-fold). Carbonic anhydrase 1 (CA1) was downregulated 179-fold. Phospholipase A2 (PLA2G12B) was downregulated 133-fold. Alanyl aminopeptidase (ANPEP) was downregulated 90-fold. Sucrase isomaltase (SI) was downregulated 57 -fold. These downregulations in the zinc treatment group contrast with reported upregulations in Barrett's neoplastic progression as described in the Discussion.

\section{miRNA Microarrays}

Additional RNA microarray analyses conducted on zinctreated Barrett's tissue focused on micro-RNA (miRNA) content of Barrett's epithelial biopsies (as described in Methods section), examining over 800 different miRNA species in each patient's tissue samples, and again comparing Barrett's metaplasia tissue biopsies from 6 zinc-treated Barrett's patients versus 6 patients receiving placebo medication. This was a different set of 12 patients from those that contributed biopsy tissue for the messenger RNA microarrays described above. Their demographic characteristics are shown in Table 1. The vast majority of the results for individual miRNA species in these 12 patients exhibited no statistically significant difference between the zinc group versus the placebo group. In fact, only 10 (of 800) miRNAs exhibited a difference between the two treatment groups that rose to statistical significance $(P<0.05$, two-sided Student's $t$ test). Results of 7 of those miRNA species (miR-125b-5P, $-132-3 \mathrm{P},-548 \mathrm{z},-551 \mathrm{a},-504,-518 \mathrm{~b}$, and $-34 \mathrm{a}-5 \mathrm{P})$ are shown in Fig. 2, with miRNA data portrayed as vertical point plots, each data point signifying a particular Barrett's patient.
Given standard probabilities, it is not remarkable that 10 of 800 miRNAs might randomly exhibit a statistically significant difference between two groups. What is unusual here is that the miRNAs in question were uniformly upregulated in the zinc treatment group in all ten cases and that 7 of these 10 miRNA species (Fig. 2) are classed as tumor suppressor miRNAs in the published literature, as discussed below.

There were cases of individual miRNAs that exhibited a trend toward downregulation in the zinc treatment group, such as miR-21-5P (a 38\% decrease) and miR-31-5P (a 33\% decrease), but these failed to achieve statistical significance $(P<0.15)$ (data not shown). Both miR-21-5P and miR-31-5P have exhibited zinc-induced decreases in the esophageal mucosae of rats [52].

\section{Protein Expression}

Barrett's biopsy tissue samples from an independent group of $8 \mathrm{BE}$ patients (4 zinc-treated and 4 placebo-treated) (demographic characteristics in Table 1) were analyzed for any observed patterns (zinc vs placebo) of protein expression by PAGE and Western blot for a variety of cancer-relevant proteins. Immunoblot analyses performed for the pro-apoptotic protein, BAX (Fig. 3a) showed higher BAX levels in biopsy tissues from the zinc-treated group. Band density determinations are shown in Fig. 3b, and the differences between zinc and placebo treatment groups are shown to be close to statistical significance $(P<0.1$, Student's $t$ test, one-tailed, $n=4$ per group). This suggests potentially increased apoptotic surveillance in Barrett's tissue in the zinc treatment group. We analyzed BCL-2 levels in a separate group of 4 zinc-treated patients and 4 placebo controls and observed lower BCL-2 levels in the zinc treatment group. However, histology on these Barrett's biopsies failed to show true secretory columnar epithelia in all cases, unlike the BAX group, all of which were true secretory epithelia.

We found that if we limited our Western immunoblot data to only those patients (biopsies) for which we were able to obtain simultaneous histological confirmation of secretory intestinal epithelia, other zinc-dependent patterns could be seen. Figure 4 shows the results for two such proteins, the tight junctional protein, CLAUDIN-7, and the pro-angiogenic receptor protein, VEGF-R2. In the case of CLAUDIN-7, a statistically significant $40 \%$ increase was observed in the zinc-treated group. In the case of VEGF-R2, a 30\% decrease was observed in the zinc treatment group, which was near the threshold of statistical significance. 
(a) $\mathrm{Bax}$



(b)

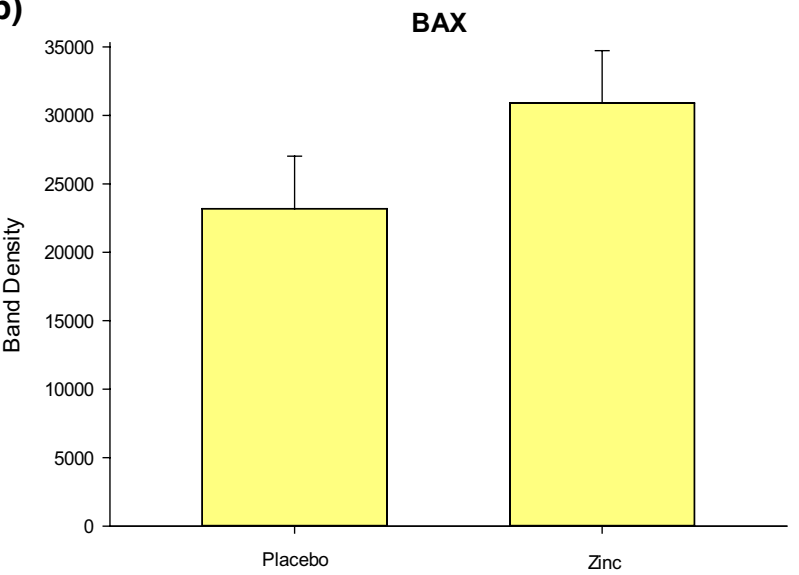

Fig. 3 Effect of zinc on the pro-apoptotic protein, BAX. a Western blot bands for BAX are shown for biopsy tissue from four zinctreated patients $(Z)$ and four placebo-treated patients $(P)$, with cell lysates prepared and PAGE and immunoblots performed as described in Methods section, b densitometry of above bands expressed as mean \pm SEM $(P<0.1$, Student's $t$ test, one-tailed, $n=4)$. Densitometry that was conducted on a Memcode stain of total protein served as the loading control for each band (lane)

\section{Discussion}

From previous studies of the effect of zinc on epithelial barrier function [41] and specifically tight junctions (TJs), it is obvious that zinc at an approximate $50 \mu \mathrm{M}$ concentrationapproximately $10 \times$ the normal level of zinc in plasma or cell culture medium containing $10 \%$ serum-is acting very much like a "drug." Zinc is apparently activating intracellular signaling and transcriptional pathways that are quiescent at a $5 \mu \mathrm{M}$ zinc level (the normal blood zinc level). In the case of barrier function, this results in modified TJ complexes that are superior-less leaky-to those in the basal state [42-44, 54]. We suspect that this is simply a result of standard Michaelis-Menten kinetics coupled with a wide variation in protein affinities for zinc, i.e., a wide variation in the $K_{m}$ values of cellular proteins for zinc. In other words, the wide range of binding affinities for zinc (their $K_{m}$ ) exhibited by the many various signaling proteins/binding proteins/ transcription factors in somatic cells can result in certain proteins (and pathways) becoming active at $50 \mu \mathrm{M}$ zinc, that are inactive at $5 \mu \mathrm{M}$ zinc. This is very important given that a toxic action of zinc is not seen until concentrations above $150 \mu \mathrm{M}$ - a limiting level that correlates roughly in humans
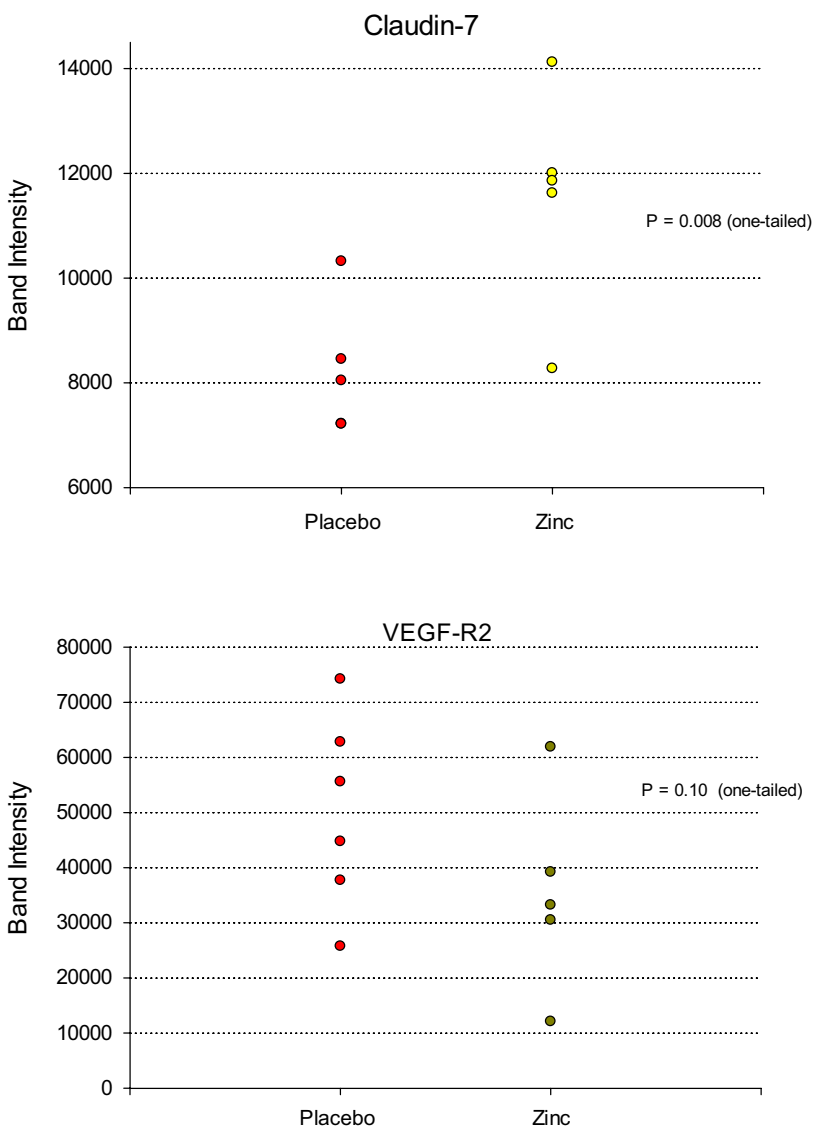

Fig. 4 Effect of zinc on the tight junctional protein, CLAUDIN-7, and the VEGF receptor protein, VEGF-R2, in biopsy tissue samples confirmed histologically as secretory intestinal metaplasia. Densitometry of Western blot bands for the proteins, CLAUDIN-7 and VEGF-R2, expressed as vertical point plots. Each data point represents the Western blot band density obtained from PAGE and immunoblots performed on whole cell lysates of biopsy tissue from a single patient. Patients were zinc-treated or placebo-treated as described in Methods, but the patient groups here consisted only of BE cases confirmed histologically as secretory intestinal metaplasia. $P$ values represent Student's $t$ tests, one-tailed, $n=5$. Densitometry conducted on a Memcode stain of total protein served as the loading control for each band (lane)

with a zinc intake of $150 \mathrm{mg} / \mathrm{adult} / \mathrm{day}$, one-third the level of zinc administered in this study [35].

\section{Zinc-Induced mRNA Changes}

As revealed in the mRNA-seq analyses, the two most prominent general actions of zinc treatment on Barrett's mucosal tissue were an anti-inflammatory activity and an anti-EMT activity. The documented role of inflammationmediated genetic and epigenetic alterations in Barrett's carcinogenesis and the role of inflammation in cancer generally have been the subject of many reviews $[55,56]$. Statistically significant downregulation of the interleukin-1 receptor, the interleukin-2 receptor, the interleukin- 3 
receptor, the interleukin-7 receptor, the interleukin-15 receptor, the interleukin-17 receptor, and the interferon gamma receptor as shown in Fig. 1 are all indications of an anti-inflammatory action of zinc on Barrett's tissue. So too are significant downregulations of actual proinflammatory cytokines in zinc-treated Barrett's tissue, such as interleukin-32, interleukin-15, interleukin-7, interleukin1-beta, and lymphotoxin-beta. Significant zinc-associated upregulations of interleukin receptor antagonists, namely the interleukin 1 receptor antagonist and the interleukin 36 receptor antagonist, would further substantiate this general anti-inflammatory program being conducted by zinc in Barrett's tissue.

The second general regulatory theme being modified by zinc is even more compelling regarding BE neoplastic progression and that is epithelial-to-mesenchymal transition (EMT). EMT's integral involvement in Barrett's neoplastic progression has been very recently reviewed [57]. It is therefore highly noteworthy that oral zinc administration downregulated so many intermediates-in/inducers-of the overall process of EMT in Barrett's tissue, such as LIF, MYB, LYN, MTA1, Indian Hedgehog and SRC, and possibly SNAIL1 and TWIST1 as well (Fig. 1). Hedgehog signaling activation is thought to be an early molecular event in the development of esophageal adenocarcinoma and in EMT signaling generally $[58,59]$. Gene profiling data have identified LYN as a key gene in the BE-adenocarcinoma axis [60]. SNAIL and TWIST have both been observed to be abundantly expressed in esophageal adenocarcinoma [61]. Increased MYB expression has been observed to be linked to expression of EMTassociated genes in breast cancer cells [62]. Likewise, LIF overexpression in tumor cells is linked to EMT, with resulting increased expression of mesenchymal markers and decreased expression of epithelial markers, an activity dependent by the way upon miR-21 function [63]. Src has been observed to promote EGF-stimulated EMT [64]. Protein kinase $\mathrm{C}-\alpha$, which is downregulated here by zinc in Barrett's tissue both as a transcript (Fig. 1) and as a protein [46], has been implicated in the regulation of EMT as well, with PKC- $\alpha$ silencing leading to a reduction in expression of EMT markers such as SNAIL and TWIST [65].

The zinc-induced, statistically significant upregulations of bone morphogenetic protein 7 (BMP7), grainyhead-like 1, and secreted frizzled-related protein 1 also serve to support this platform of EMT suppression, with the SFRP1 gene being methylated and silenced in Barrett's progression, and BMP7 actively inhibiting TGF-beta signaling in esophageal cancer cells [66-68]. Grainyhead-like-2 has been downregulated in breast cancer cells and has been observed to suppress EMT in these cells [69]. Metastasis suppressor-1 (MTSS1), upregulated 2.25-fold in the zinc treatment group, has been inversely linked to EMT and is known to inhibit epithelial junction disassembly [70].
The significant 2.25-fold downregulation of the transcript for TNF receptor-associated factor, TRAF1, in Barrett's tissue (Fig. 1), could be considered additive to the overall pro-apoptotic effect of zinc treatment in reducing levels of BCL-2 protein while also increasing levels of BAX protein (Fig. 3), given the widely reported anti-apoptotic activity of TRAF1 [71]. Collectively, these data may suggest that zinc is acting to increase apoptotic surveillance in Barrett's tissue.

Not every transcriptional change induced by zinc was, however, consistent with a cancer chemopreventive narrative. For example, although kallikreins were typically downregulated in the zinc treatment group (KLK3 [84-fold]; KLK15 [27-fold]; KLK1 [fivefold])—a positive outcome for inhibition of neoplastic progression in BE [72]—-there were other kallikreins that were observed to upregulate in the zinc treatment group, such as KLK10 (7.3-fold) (data not shown). However, it was also observed by the same group that there were a number of serpin peptidase inhibitors (e.g., SERPINB11; 41-fold increase) whose dramatic upregulation might counter the activity of any upregulated kallikrein enzymes.

\section{Zinc-Induced miRNA Changes}

The miRNA microarrays performed on Barrett's biopsy tissue from 6 zinc-treated patients versus 6 placebo-treated patients provided information on over 800 individual miRNA species. Many of those miRNAs $(10-15 \%$ of the total miRNAs reported on) showed a statistical trend in the data regarding a difference in miRNA expression between the zinc group and the placebo group $(P<0.15)$. However, only 10 of those miRNAs exhibited a difference between the zinc and placebo groups that rose to the level of statistical significance $(P<0.05)$. Seven of those miRNAs are shown in Fig. 2. These seven are of particular interest in the context of a study focusing on preneoplastic tissue because they are classed in the published literature as tumor suppressor miRNAs, and all seven are significantly upregulated in the zinc treatment group. miR-34a-5P was elevated only $80 \%$ in the zinc treatment group-the smallest increase in our set of seven-but has perhaps the most extensive tumor suppressor profile in the published literature. This microRNA is known to inhibit colorectal cancer cell growth, migration, and invasion [73]. It likewise inhibits tumorigenesis in nonsmall cell lung cancer cells [74]. miR-125b-5P increased approximately twofold in the zinc group and is known to be downregulated in triple negative breast cancer cells [75, 76]. It is also downregulated in esophageal adenocarcinoma and bladder cancer [77, 78]. Most significantly here, miR$125 \mathrm{~b}-5 \mathrm{P}$ has been reported to inhibit various signaling elements of EMT in Barrett's metaplasia [57]. miR-132-3P, also doubled in the zinc group, and is known to exert an 
inhibitory role on growth of gastric cancer cells through inhibition of CD80, which itself aids dysplastic progression in colorectal cancer $[79,80]$. miR-504 showed a tenfold elevation in the zinc group. Its downregulation correlates with a poor prognosis in hepatocellular carcinoma [81]. It is also downregulated in pharyngeal squamous cell carcinomas [82]. Its inhibition in pancreatic cancer cells increased their migration and invasiveness [83]. Higher levels of miR504 in neuroendocrine tumors correlated with lower tumor grades [84]. However, miR-504 is also a known repressor of p53 expression [85]. p53 activation correlated with downregulation of miR-504 [86]. miR-518b levels were elevated twofold in the zinc group. This miRNA is downregulated in esophageal squamous cell carcinoma and is known to suppress cancer growth by inducing apoptosis of cancer cells [87]. It likewise inhibits cancer cell motility [88]. It also downregulates FOXN1 and suppresses EMT [89]. miR-548z increased over tenfold in the zinc group and is regarded as a general tumor suppressor with known involvement in cell replication $[9,90]$. miR-551a-elevated fivefold with zinc treatment-is downregulated in gastric adenocarcinomas and inhibits cancer cell migration invasiveness [91]. It has been reported to suppress metastases of colorectal cancers to the liver [92]. Its decrease in cancer cells may be important in their bioenergetics and metabolism [93].

Although the decreases of miR-21-5P and miR-31-5P in our study as a result of zinc treatment were not statistically significant $(P<0.15)$, it is noteworthy that the trend for these two miRNA species is down in the zinc treatment group (for miR-21-5P, a 38\% decrease; for miR-31-5P, a 33\% decrease (2694 \pm 770 [placebo] vs $1678 \pm 412$ [zinc-treated]; $46 \pm 12$ [placebo] vs $31 \pm 8$ [zinc-treated]). In esophageal chemical carcinogenesis studies in rodents, these two miRNA species have increased in both states of zinc deficiency and in neoplasia [29]. Moreover, these two miRNAs have been shown to play potential mechanistic roles in development of oral, urinary bladder, lung, colorectal, and hepatocellular cancers [94-98].

\section{Zinc-Induced Protein Changes}

Western blots were performed on whole-cell lysates of esophageal biopsy tissue samples from a group of 4 zinctreated and 4 placebo-treated patients as described in Methods sections. Densitometry of immunoblot bands, however, did not generally evidence a statistically significant difference between the two groups, with significant variability in the data. Lack of either a trend or statistical difference was seen for the proteins: cyclin-D1, COX-2, HIF-1 $\alpha$, occludin, and claudins $2,3,5$, and 18 . The pro-apoptotic protein, BAX, however, evidenced a trend in its data, which rose close to statistical significance $(P<0.1)$ (Fig. 3). A trend in band intensity data was observed indicating increased BAX expression in the tissue of the zinc-treated group, which could indicate increased apoptotic activity in the zinctreated Barrett's tissue. A correspondingly inverse trend was observed for BCL-2 expression which decreased in the zinc treatment group (data not shown). Failure to achieve true statistical significance in both cases $(P<0.1)$ could reflect our small sample size as well as the inherent variability of patient-based samples compared, for example, to animal studies (variability in gender, age, ethnicity, diet, current medications, etc.), as discussed below. A greater $\mathrm{n}$ value would be needed here to offset this inherent variability (see the demographic tables). Heightened apoptotic surveillance could prove protective against neoplastic development and warrants attention in any future similar studies.

When we were able to work only with biopsy samples where matched histology showed true secretory intestinal epithelia - and not rely on the previous diagnosis of these patients nor on the gross appearance of the esophageal mucosa at the time of endoscopy-two other proteins that were examined exhibited a noteworthy pattern. As shown in Fig. 4, the principal vascular endothelial growth factor receptor, VEGF-R2, exhibited a 30\% decrease in Barrett's tissue in zinc-treated patients. As VEGF-R2 is pivotal in processes favoring neoplastic progression-such as angiogenesis-it is noteworthy that zinc is inducing decreased VEGF-R2 levels in this preneoplastic tissue. Zhang et al. [99] highlight the role of VEGF-R2 in neoplastic progression in $\mathrm{BE}$ and recommend strategies to reduce autocrine VEGF signaling. Figure 4 also shows a statistically significant, $40 \%$ increase in the tight junctional protein, CLAUDIN-7, in zinc-treated Barrett's tissue. Montgomery et al. [100] reported a decreased abundance of CLAUDIN-7 expression in BE tissue transitioning from low-grade dysplasia to high-grade dysplasia and adenocarcinoma. Li et al. [101] have recently observed claudin-7-mediated inhibition of colon cancer cell invasiveness and proliferation.

\section{The Chemopreventive Designation}

In this publication, it should be noted that we have employed a loose definition of "chemopreventive" as it relates to the observed, zinc-induced molecular changes in signaling proteins, transcription factors, regulator micro RNAs, etc. The published literature might suggest that these various upregulations and downregulations may mitigate against cancer development in a tissue ("chemopreventive") based upon the known phenotypic functionality that these genes/proteins manifest. For example, genes/proteins known to have an inhibitory effect on epithelial-to-mesenchymal transition (EMT) within cells might reasonably be expected to oppose neoplastic development in cells/tissues. However, if one defines chemopreventive more strictly, as signifying changes in cells/tissues that actually result in decreased mortality in 
a specific type of cancer as seen in, e.g., a Kaplan-Meier curve, then it is true that our present study comes up short of that definition. We clearly state in this paper that this study would need to be followed up by a true clinical trial regarding zinc's ability to decrease EAC appearance and/or EAC-related deaths coming out of zinc-treated patients with Barrett's. For this reason among others, we specifically term our study, a pilot study.

\section{The Inherent Problems in a Clinical Study with Low $n$ Values (Patient and Biopsy Heterogeneity)}

Due to the difficulties in finding - and recruiting-suitable and compliant patients in this study, recruitment of the individual patient groups in our study made no attempt to exclude on the bases of age (35-80), gender, ethnicity, or medications (except for those medications that could be inhibited by zinc). Our only dietary exclusion was to eliminate vegans due to their potentially low zinc intake. Along with the variability that the above differences could introduce into the data sets, there was an added element of variability in the biopsy collections themselves. For any individual patient, a total of four biopsies of Barrett's tissue were pooled together to provide enough biological material for analyses (mRNA, miRNA, or protein). The endoscopist needed therefore to obtain 4 individual biopsy samples that were truly Barrett's tissue, i.e., above the Z-line and yet below where the Barrett's region ended and normal esophageal mucosa began. For long-segment BE, this was not a major issue, but for short-segment BE cases less than $2 \mathrm{~cm}$, and more particularly cases of discontinuous BE, obtaining accurate BE tissue samples could be problematic. This is even more true when tissue bleeding begins after obtaining the initial biopsy sample. In summary, it is very possible that in certain individual cases, a non-Barrett's biopsy (gastric cardia or stratified squamous esophageal mucosa) may have been included in with the four-biopsy-set. Given the possibility of this eventuality in certain cases, plus the variability that accrues with a human population sample (variability of age, gender, ethnicity, genetics, medications), it is not surprising that data variation was large, especially in the Western blot data. One would in fact expect more variability in the protein (Western) data compared to the RNA data due to the greater number of synthesis steps involved (translation and post-translational modification), along with the regulation of such steps. Indeed, this was the case when one compares the results of Figs. 1 and 2 versus Figs. 3 and 4.

In the short patient history that was taken as part of the study, we noted whether test patients took multivitamins containing zinc, oral zinc supplements (pills or capsules), used a zinc-containing anti-dandruff shampoo, or used denture adhesive (occasionally high in zinc). Such occurrences were rare but were noted in each patient's file. An obvious effect of any of these usages on data sets was however not observed, although the small sample size of the data sets makes certainty difficult.

In discussing the inherent variability that accompanies patient-based studies with the large variability in tissue samples from one patient to the next, it is worth asking why not utilize an animal model of BE. We would point out that in this study's miRNA, mRNA, and especially its protein (Western immunoblot) analyses, data variability was large. However, the magnitude of zinc effects on specific mRNA or miRNA species was sufficiently large to see an effect of zinc despite the variability. This serendipitous fact plus the ready availability of esophageal tissue biopsies from medically driven, surveillance EGDs, makes it compelling to utilize human study subjects for this project. In addition, there is the issue to consider of the shortcomings in each and every animal model of $\mathrm{BE}$, in terms of accurately mirroring the actual tissue of interest, namely true Barrett's metaplasia [29].

The relatively small sample size $(n)$ in the various molecular analyses (mRNA, miRNA, protein) reported here is inarguably a valid criticism of our work. However, there are several worthwhile points that can be highlighted concerning the sample size and justified conclusions that can be reached from the data presented. With an $n=5$ in the mRNA arrays (heatmaps), the odds for any given individual gene transcript (e.g., MYB) being, e.g., lower for 4 of 5 patients in the zinc treatment group (compared to the placebo group) are actually not very high ( 1 in 16 ) (i.e., $1 / 2 \times 1 / 2 \times 1 / 2 \times 1 / 2$ ). However, the more correct issue is that across the 27,000 gene transcripts that were analyzed here, the odds are not that low that 1459 random transcripts might, for example, be significantly decreased in the zinc treatment group (the actual results that we reported above) given that we are considering an $n$ equal to only 5 in the treatment group. If the core finding of this study was that zinc treatment significantly decreased 1459 random transcripts among 27,000 transcripts analyzed, one could reasonably pronounce a judgment of underpowered and thereby end all discussion of biomedical significance. However, there are other issues at play in the data presented here.

The first and most powerful is that with regard to cancer risk, many of these zinc-induced gene expression changes did not appear to be random upon analysis of the nature of the changes induced. As shown in Fig. 1, there was a pattern in many of the changes, namely upregulations of transcripts that have been shown in the literature to have a tumor suppressive quality, while also downregulations of transcripts that have been shown to have a tumor promotional quality. Thus, what is at issue here is not simply biomedical significance surrounding zinc-induced change per se, but rather based on the nature of the specific change that zinc produced. 
Secondly, the mRNA transcriptional changes in Fig. 1 do not stand on their own in this study. They are supported by the additional studies (Figs. 2, 3 and 4) showing changes in specific micro-RNA species (miR-34a-5P, etc.) and specific protein species (BAX, VEGF-R2, Claudin-7) determined independently - and in independent patient groups - that support the same overall pattern, namely that zinc may be exerting a cancer-inhibitory effect here.

Thirdly, the observations reported here for mRNA, miRNA, and protein do not stand on their own collectively. This manuscript describes a very large published literature reporting investigations in various animal models that make a similar conclusion - that orally administered zinc can exert a protective effect regarding esophageal cancer development. It is the influence of this combined evidence that supports the data presented here and is in the end persuasive here.

A final consideration, however, is that this work is a pilot study. This work will-like most research—need to stand the test of time. Other future zinc studies regarding esophageal cancer in humans will need to be performed. This study can only be validated in the end by an actual clinical prospective trial that manages to show lower rates of EAC in a large cohort of Barrett's patients treated with zinc (administered as was done here) for considerable periods of time. Only then can not only the chemopreventive label be justifiably used, but the final validation of the molecular changes shown here can then be made.

\section{Summary}

Western immunoblot results in this study suggest that oral zinc administration as described herein can promote apoptotic surveillance of Barrett's epithelia, a beneficial effect in a cell population with increased neoplastic potential. Zinc treatment also resulted in two additional and compelling effects in Barrett's epithelia, revealed in RNA microarray studies: (1) significant upregulations of microRNA species that have well-documented tumor suppressor activity; (2) significant upregulations and downregulations of specific messenger RNA species whose net effect would be a decreased inflammatory state in the tissue and decreased EMT signaling in the cells. Both effects would mitigate against neoplastic progression. Overall, this study suggests that daily zinc prophylaxis could be a significant proactive step that a Barrett's esophagus patient could take to reduce their lifetime risk of EAC. This is particularly important given studies such as [102] that indicate PPI medications may not afford the esophageal cancer protection that was once thought for the BE patient.

Acknowledgments We are first and foremost indebted to the many Barrett's esophagus patients of the Main Line Gastroenterology Associates practice who consented to participate in this study and provide the study with BE biopsy samples. We are likewise extremely grateful to the nurses and anesthesia personnel of the Main Line Gastroenterology Endoscopy Center (Bala Cynwyd, PA) and the Endoscopy Procedures Unit of Lankenau Medical Center for their help and patience in obtaining these esophageal biopsies. The expert assistance and patience of Ms. Sandy Alyanakian and Ms. Terri Olshefski in editing the many drafts and iterations of this manuscript and its figures was tremendously helpful. We are very grateful to Dr. Mazen Soliman and Ms. Kary Heller for their help in obtaining the many publications cited in this paper. We are very happy to acknowledge the longstanding Grant support of the Sharpe Strumia Foundation (to J.M.M. and G.M.) without which this study could not have been undertaken. This work was also supported by NIH Grant (R01CA118560 (to LYF) and an NIH Cancer Center Support Grant (CCSG) (P30 CA010815) to support the Wistar Institute Genomics and Bioinformatics Facility.

\section{Compliance with Ethical Standards}

Conflict of interest The authors declare no conflicts of interest regarding this project or its findings.

Open Access This article is licensed under a Creative Commons Attribution-NonCommercial 4.0 International License, which permits any non-commercial use, sharing, adaptation, distribution and reproduction in any medium or format, as long as you give appropriate credit to the original author(s) and the source, provide a link to the Creative Commons licence, and indicate if changes were made. The images or other third party material in this article are included in the article's Creative Commons licence, unless indicated otherwise in a credit line to the material. If material is not included in the article's Creative Commons licence and your intended use is not permitted by statutory regulation or exceeds the permitted use, you will need to obtain permission directly from the copyright holder.To view a copy of this licence, visit http://creativecommons.org/licenses/by-nc/4.0/.

\section{References}

1. Surveillance, epidemiology, and end results (SEER) program populations (1969-2016) (www.seer.cancer.gov/popdata), National Cancer Institute, DCCPS, Surveillance Research Program, released December 2017.

2. Coleman HG, Xie SH, Lagergren J. The epidemiology of esophageal adenocarcinoma. Gastroenterology. 2018;154:390-405.

3. Amadi C, Gatenby P. Barrett's oesophagus: current controversies. World J Gastroenterol. 2017;23:5051-5067.

4. Lagergren J, Bergström R, Lindgren A, et al. Symptomatic gastroesophageal reflux as a risk factor for esophageal adenocarcinoma. $N$ Engl J Med. 1999;340:825-831.

5. El-Serag HB, Sweet S, Winchester CC, et al. Update on the epidemiology of gastro-oesophageal reflux disease: a systematic review. Gut. 2014;63:871-880.

6. Runge TM, Abrams JA, Shaheen NJ. Epidemiology of Barrett's esophagus and esophageal adenocarcinoma. Gastroenterol Clin N Am. 2015;44:203-231.

7. Strand DS, Kim D, Peura DA. 25 years of proton pump inhibitors: a comprehensive review. Gut Liver. 2017;11:27-37.

8. Tan MC, El-serag HB, Yu X, et al. Acid suppression medications reduce risk of oesophageal adenocarcinoma in Barrett's oesophagus: a nested case-control study in US male veterans. Aliment Pharmacol Ther. 2018;48:469-477. 
9. Hu B, Ying X, Wang J, et al. Identification of a tumor-suppressive human-specific microRNA within the FHIT tumor-suppressor gene. Cancer Res. 2014;74:2283-2294.

10. Woster AD, Ml F, Taylor MW, et al. Zinc suppression of initiation of sarcoma 180 growth. J Natl Cancer Inst. 1975;54:1001-1003.

11. J1 P, Sheridan PJ. Effect of zinc administration on the growth of L1210 and BW5147 tumors in mice. J Natl Cancer Inst. 1976;57:361-363.

12. Dhawan DK, Chadha VD. Zinc: a promising agent in dietary chemoprevention of cancer. Indian J Med Res. 2010;132:676-682.

13. Narayanan BA. Chemopreventive agents alters global gene expression pattern: predicting their mode of action and targets. Curr Cancer Drug Targets. 2006;6:711-727.

14. Van Rensburg SJ, Hall JM, Gathercole PS. Inhibition of esophageal carcinogenesis in corn-fed rats by riboflavin, nicotinic acid, selenium, molybdenum, zinc, and magnesium. Nutr Cancer. 1986;8:163-170.

15. Poswillo DE. Inhibition of chemical carcinogenesis in the hamster cheek pouch by zinc sulphate in the drinking water. Trans Int Conf Oral Surg. 1973;4:143-146.

16. Epstein J. SV40-transformed human cells fail to grow in zinc concentrations which permit normal human fibroblast proliferation. J Cell Physiol. 1982;110:17-22.

17. Moulahoum H, Boumaza BMA, Ferrat M, et al. Aberrant crypt foci are regionally affected by zinc treatment in a 1,2-dimethylhydrazine induced colon carcinogenesis model. J Trace Elem Med Biol. 2018;47:21-30. https://doi.org/10.1016/j.jtemb .2018.01.009.

18. Dani V, Goel A, Vaiphei K, Dhawan DK. Chemopreventive potential of zinc in experimentally induced colon carcinogenesis. Toxicol Lett. 2007;171:10-18.

19. Chadha VD, Garg ML, Dhawan D. Influence of extraneous supplementation of zinc on trace elemental profile leading to prevention of dimethylhydrazine-induced colon carcinogenesis. Toxicol Mech Methods. 2010;20:493-497. https://doi. org/10.3109/15376516.2010.511300.

20. Singh CK, Pitschmann A, Ahmad N. Resveratrol-zinc combination for prostate cancer management. Cell Cycle. 2014;13:1867-1874. https://doi.org/10.4161/cc.29334.

21. Banudevi S, Elumalai P, Arunkumar R, et al. Chemopreventive effects of zinc on prostate carcinogenesis induced by $\mathrm{N}$-methyl$\mathrm{N}$-nitrosourea and testosterone in adult male Sprague-Dawley rats. J Cancer Res Clin Oncol. 2011;137:677-686. https://doi. org/10.1007/s00432-010-0926-4.

22. da Silva FR, Dias MC, Barbisan LF, Rodrigues MA. Lack of protective effects of zinc gluconate against rat colon carcinogenesis. Nutr Cancer. 2013;65:571-577. https://doi. org/10.1080/01635581.2013.775317.

23. Fong LY, Jiang Y, Farber JL. Zinc deficiency potentiates induction and progression of lingual and esophageal tumors in p53-deficient mice. Carcinogenesis. 2006;27:1489-1496.

24. Fong LY, Li JX, Farber JL, et al. Cell proliferation and esophageal carcinogenesis in the zinc-deficient rat. Carcinogenesis. 1996; 17:1841-1848.

25. Fong LY, Jiang Y, Rawahneh ML, et al. Zinc supplementation suppresses 4-nitroquinoline 1-oxide-induced rat oral carcinogenesis. Carcinogenesis. 2001;32:554-560.

26. Sun J, Liu J, Pan X, et al. Effect of zinc supplementation on $\mathrm{N}$-nitrosomethylbenzylamine-induced forestomach tumor development and progression in tumor suppressor-deficient mouse strains. Carcinogenesis. 2011;32:351-358.

27. Kang JH, Luben R, Alexandre L, et al. Dietary antioxidant intake and the risk of developing Barrett's oesophagus and oesophageal adenocarcinoma. $B r J$ Cancer. 2018;118:1658-1661.
28. Grotenhuis BA, Franken PF, Swinkels WJ, et al. Early morbidity encountered in the dietary-related mouse model of Barrett's esophagus: a question of zinc? Dis Esophagus. 2011;24:371-373.

29. Kapoor H, Lohani KR, Lee TH, Agrawal DK, Mittal SK. Animal models of Barrett's esophagus and esophageal adenocarcinomapast, present, and future. Clin Transl Sci. 2015;8:841-847. https ://doi.org/10.1111/cts.12304.

30. Powell SR. The antioxidant properties of zinc. J Nutr. 2000;130:1447S-1454S. https://doi.org/10.1093/jn/130.5.1447S.

31. Ooi TC, Chan KM, Sharif R. Antioxidant, anti-inflammatory, and genomic stability enhancement effects of zinc 1-carnosine: a potential cancer chemopreventive agent? Nutr Cancer. 2017;69:201-210. https://doi.org/10.1080/01635581.2017.12651 32.

32. Kim SY, Kim JW, Ko YS, Koo JE, Chung HY, Lee-Kim YC. Changes in lipid peroxidation and antioxidant trace elements in serum of women with cervical intraepithelial neoplasia and invasive cancer. Nutr Cancer. 2003;47:126-130.

33. Gopalakrishna R, Jaken S. Protein kinase $\mathrm{C}$ signaling and oxidative stress. Free Radic Biol Med. 2000;28:1349-1361.

34. Jaiswal AS, Narayan S. Zinc stabilizes adenomatous polyposis coli (APC) protein levels and induces cell cycle arrest in colon cancer cells. J Cell Biochem. 2004;93:345-357.

35. Fosmire GJ. Zinc toxicity. Am J Clin Nutr. 1990;51:225-227.

36. Samman S, Roberts DC. The effect of zinc supplements on plasma zinc and copper levels and the reported symptoms in healthy volunteers. Med J Aust. 1987;146:246-249.

37. Bogden JD, Oleske JM, Lavenhar MA, et al. Zinc and immunocompetence in elderly people: effects of zinc supplementation for 3 months. Am J Clin Nutr. 1988;48:655-663.

38. Fraga CG, Oteiza PI, Keen CL. Trace elements and human health. Mol Aspects Med. 2005;26:233-234.

39. Karam SM. Lineage commitment and maturation of epithelial cells in the gut. Front Biosci. 1999;4:D286-D298.

40. Pan Q, Nicholson AM, Barr H, et al. Identification of lineageuncommitted, long-lived, label-retaining cells in healthy human esophagus and stomach, and in metaplastic esophagus. Gastroenterology. 2013;144:761-770. https://doi.org/10.1053/j.gastr o.2012.12.022

41. Rybakovsky E, Valenzano MC, Deis R, et al. Improvement of human-oral-epithelial-barrier function and of tight junctions by micronutrients. J Agric Food Chem. 2017;65:10950-10958.

42. Valenzano MC, DiGuilio K, Mercado J, et al. Remodeling of tight junctions and enhancement of barrier integrity of the CACO-2 intestinal epithelial cell layer by micronutrients. PloS One. 2015;10: 0133926.

43. Wang X, Valenzano MC, Mercado JM, et al. Zinc enhancement of LLC-PK(1) renal epithelial barrier function. Clin Nutr. 2014;33:280-286.

44. Wang X, Valenzano MC, Mercado JM, et al. Zinc supplementation modifies tight junctions and alters barrier function of CACO-2 human intestinal epithelial layers. Dig Dis Sci. 2013;58:77-87.

45. Mercado J, Valenzano MC, Jeffers C, et al. Enhancement of tight junctional barrier function by micronutrients: compound-specific effects on permeability and claudin composition. PLoS One. 2013;8:e78775. https://doi.org/10.1371/journal.pone.0078775.

46. Valenzano MC, Mercado JM, Wang X, et al. Drug delivery of zinc to Barrett's metaplasia by oral administration to Barrett's esophagus patients. Ther Deliv. 2014;5:257-264.

47. Langmead B, Salzberg SL. Fast gapped-read alignment with Bowtie 2. Nat Methods. 2012;9:357-359.

48. Li B, Dewey CN. RSEM: accurate transcript quantification from RNA-Seq data with or without a reference genome. BMC Bioinform. 2011;12:323. 
49. Love MI, Huber W, Anders S. Moderated estimation of fold change and dispersion for RNA-seq data with DESeq2. Genome Biol. 2014;15:550.

50. Geiss GK, Bumgarner RE, Birditt B, et al. Direct multiplexed measurement of gene expression with color-coded probe pairs. Nat Biotechnol. 2008; https://doi.org/10.1038/nbt1385.

51. Wyman SK, Knouf EC, Parkin RK, et al. Post-transcriptional generation of miRNA variants by multiple nucleotidyl transferases contributes to miRNA transcriptome complexity. Genome Res. 2011;21:1450-1461. https://doi.org/10.1101/gr.118059.110.

52. Alder H, Taccioli C, Chen H, et al. Dysregulation of miR-31 and miR-21 induced by zinc deficiency promotes esophageal cancer. Carcinogenesis. 2012;33:1736-1744.

53. Aldridge GM, Podrebarac DM, Greenough WT, et al. The use of total protein stains as loading controls: an alternative to highabundance single-protein controls in semi-quantitative immunoblotting. J Neurosci Methods. 2008;172:250-254.

54. Roscioli E, Jersmann HP, Lester S, et al. Zinc deficiency as a codeterminant for airway epithelial barrier dysfunction in an ex vivo model of COPD. Int J Chronic Obstr Pulm Dis. 2017; 12:3503-3510.

55. Poehlmann A, Kuester D, Malfertheiner P, et al. Inflammation and Barrett's carcinogenesis. Pathol Res Pract. 2012;208:269-280.

56. Thun MJ, Henley SJ, Gansler T. Inflammation and cancer: an epidemiological perspective. Novartis Found Symp. 2004;256:6-21. (discussion 22-28, 49-52, 266-269).

57. Clark RJ, Craig MP, Agrawal S, et al. MicroRNA involvement in the onset and progression of Barrett's esophagus: a systematic review. Oncotarget. 2018;9:8179-8196.

58. Yang $\mathrm{MH}$, Lin $\mathrm{BR}$, Chang $\mathrm{CH}$, et al. Connective tissue growth factor modulates oral squamous cell carcinoma invasion by activating a miR-504/FOXP1 signalling. Oncogene. 2012;31:2401-2411.

59. Katoh Y, Katoh M. Hedgehog signaling, epithelial-to-mesenchymal transition and miRNA (review). Int J Mol Med. 2008;22:271-275.

60. Liu D. LYN, a key gene from bioinformatics analysis, contributes to development and progression of esophageal adenocarcinoma. Med Sci Monit Basic Res. 2015;21:253-261.

61. Tomizawa Y, Wu TT, Wang KK. Epithelial mesenchymal transition and cancer stem cells in esophageal adenocarcinoma originating from Barrett's esophagus. Oncol Lett. 2012;3:1059-1063.

62. Cesi V, Casciati A, Sesti F, et al. TGF $\beta$-induced c-Myb affects the expression of EMT-associated genes and promotes invasion of ER + breast cancer cells. Cell Cycle. 2011;10:4149-4161.

63. Yue X, Zhao Y, Zhang C, et al. Leukemia inhibitory factor promotes EMT through STAT3-dependent miR-21 induction. Oncotarget. 2016;7:3777-3790.

64. Zhao L, Li X, Song N, et al. Src promotes EGF-induced epithelial to-mesenchymal transition and migration in gastric cancer cells by upregulating ZEB1 and ZEB2 through AKT. Cell Biol Int. 2018;42:294-302.

65. Abera MB, Kazanietz MG. Protein kinase $\mathrm{C} \alpha$ mediates erlotinib resistance in lung cancer cells. Mol Pharmacol. 2015;87:832-841.

66. Rees JR, Onwuegbusi BA, Save VE, et al. In vivo and in vitro evidence for transforming growth factor-beta1-mediated epithelial to mesenchymal transition in esophageal adenocarcinoma. Cancer Res. 2006;66:9583-9590. (Erratum in: Cancer Res. 2007;67:427).

67. Mlacki M, Kikulska A, Krzywinska E, et al. Recent discoveries concerning the involvement of transcription factors from the Grainyhead-like family in cancer. Exp Biol Med (Maywood). 2015;240:1396-1401.
68. Clément G, Braunschweig R, Pasquier N, et al. Alterations of the Wnt signaling pathway during the neoplastic progression of Barrett's esophagus. Oncogene. 2006;25:3084-3092.

69. Cieply B, Riley P 4th, Pifer PM, et al. Suppression of the epithelial-mesenchymal transition by Grainyhead-like-2. Cancer Res. 2012;72:2440-2453.

70. Dawson JC, Bruche S, Spence HJ, et al. Mtss1 promotes cell-cell junction assembly and stability through the small GTPase Rac1. PLoS One. 2012;7:e31141.

71. Zapata JM, Lefebvre S, Reed JC. Targeting TRAfs for therapeutic intervention. Adv Exp Med Biol. 2007;597:188-201.

72. Grin A, Samaan S, Tripathi M, et al. Evaluation of human tissue kallikrein-related peptidases 6 and 10 expression in early gastroesophageal adenocarcinoma. Hum Pathol. 2015;46:541-548.

73. Gao J, Li N, Dong Y, et al. miR-34a-5p suppresses colorectal cancer metastasis and predicts recurrence in patients with stage II/III colorectal cancer. Oncogene. 2015;34:4142-4152.

74. Jiang ZQ, Li MH, Qin YM. Luteolin inhibits tumorigenesis and induces apoptosis of non-small cell lung cancer cells via regulation of MicroRNA-34a-5p. Int J Mol Sci. 2018;19:447.

75. Ouyang M, Li Y, Ye S, et al. MicroRNA profiling implies new markers of chemoresistance of triple-negative breast cancer. PloS One. 2014;9:e96228.

76. Calvano Filho CM, Calvano-Mendes DC, Carvalho KC, et al. Triple-negative and luminal A breast tumors: differential expression of miR-18a-5p, miR-17-5p, and miR-20a-5p. Tumour Biol. 2014;35:7733-7741

77. Gu J, Wang Y, Wu X. MicroRNA in the pathogenesis and prognosis of esophageal cancer. Curr Pharm Des. 2013;19:1292-1300.

78. Canturk KM, Ozdemir M, Can C, et al. Investigation of key miRNAs and target genes in bladder cancer using miRNA profiling and bioinformatic tools. Mol Biol Rep. 2014;41:8127-8135.

79. Wu R, Li F, Zhu J, et al. A functional variant at miR-132-3p, miR-212-3p, and miR-361-5p binding site in CD80 gene alters susceptibility to gastric cancer in a Chinese Han population. Med Oncol. 2014;31:60.

80. Scarpa M, Brun P, Scarpa M, et al. CD80-CD28 signaling controls the progression of inflammatory colorectal carcinogenesis. Oncotarget. 2015;6:20058-20069.

81. Katoh M, Igarashi M, Fukuda $\mathrm{H}$, et al. Cancer genetics and genomics of human FOX family genes. Cancer Lett. 2013;328:198-206.

82. Kikkawa N, Kinoshita T, Nohata N, et al. MicroRNA-504 inhibits cancer cell proliferation via targeting CDK6 in hypopharyngeal squamous cell carcinoma. Int J Oncol. 2014;44:2085-2092.

83. Jiang $\mathrm{B}, \mathrm{Gu} \mathrm{Y}, \mathrm{Chen} \mathrm{Y}$. Identification of novel predictive markers for the prognosis of pancreatic ductal adenocarcinoma. Cancer Invest. 2014;32:218-225.

84. Mairinger FD, Ting S, Werner R, et al. Different micro-RNA expression profiles distinguish subtypes of neuroendocrine tumors of the lung: results of a profiling study. Mod Pathol. 2014;27:1632-1640.

85. Kumar M, Lu Z, Takwi AA, et al. Negative regulation of the tumor suppressor p53 gene by microRNAs. Oncogene. 2011;30:843-853.

86. Soutto M, Chen Z, Saleh MA, et al. TFF1 activates p53 through down-regulation of miR-504 in gastric cancer. Oncotarget. 2014;5:5663-5673.

87. Zhang M, Zhou S, Zhang L, et al. miR-518b is down-regulated, and involved in cell proliferation and invasion by targeting Rap1b in esophageal squamous cell carcinoma. FEBS Lett. 2012;586:3508-3521.

88. Liang W, Li X, Li Y, et al. Gallic acid induces apoptosis and inhibits cell migration by upregulating miR-518b in SW1353 human chondrosarcoma cells. Int J Oncol. 2014;44:91-98. 
89. Kushwaha R, Thodima V, Tomishima MJ, et al. miR-18b and miR-518b Target FOXN1 during epithelial lineage differentiation in pluripotent cells. Stem Cells Dev. 2014;23:1149-1156.

90. Piriyapongsa J, Jordan IK. A family of human microRNA genes from miniature inverted-repeat transposable elements. PloS One. 2007;2:e203.

91. Li Z, Cao Y, Jie Z, et al. miR-495 and miR-551a inhibit the migration and invasion of human gastric cancer cells by directly interacting with PRL-3. Cancer Lett. 2012;323:41-47.

92. Loo JM, Scherl A, Nguyen A, et al. Extracellular metabolic energetics can promote cancer progression. Cell. 2015;160:393-406.

93. Sullivan WJ, Christofk HR. The metabolic milieu of metastases. Cell. 2015;160:363-364.

94. Peng H, Wang L, Su Q, et al. MiR-31-5p promotes the cell growth, migration and invasion of colorectal cancer cells by targeting NUMB. Biomed Pharmacother. 2019;109:208-216.

95. Bi J, Liu H, Cai Z, et al. Circ-BPTF promotes bladder cancer progression and recurrence through the miR-31-5p/RAB27A axis. Aging (Albany NY). 2018;10:1964-1976.

96. Zeljic K, Jovanovic I, Jovanovic J, et al. MicroRNA meta-signature of oral cancer: evidence from a meta-analysis. Upsala J Med Sci. 2018;123:43-49.

97. Zhong XZ, Deng Y, Chen G, et al. Investigation of the clinical significance and molecular mechanism of miR-21-5p in hepatocellular carcinoma: a systematic review based on 24 studies and bioinformatics investigation. Oncol Lett. 2019;17:230-246.
98. Li X, Wu X. MiR-21-5p promotes the progression of non-smallcell lung cancer by regulating the expression of SMAD7. Onco Targets Ther. 2018;11:8445-8454.

99. Zhang Q, Yu C, Peng S, et al. Autocrine VEGF signaling promotes proliferation of neoplastic Barrett's epithelial cells through a PLC-dependent pathway. Gastroenterology. 2014;146:461-472.

100. Montgomery E, Mamelak AJ, Gibson M, et al. Overexpression of claudin proteins in esophageal adenocarcinoma and its precursor lesions. Appl Immunohistochem Mol Morphol. 2006;14:24-30.

101. Li W, Xu C, Wang K, et al. Non-tight junction-related function of claudin-7 in interacting with integrin $\beta 1$ to suppress colorectal cancer cell proliferation and migration. Cancer Manag Res. 2019;11:1443-1451.

102. Hvid-Jensen F, Pedersen L, Funch-Jensen P, et al. Proton pump inhibitor use may not prevent high-grade dysplasia and oesophageal adenocarcinoma in Barrett's oesophagus: a nationwide study of 9883 patients. Aliment Pharmacol Ther. 2014;39:984-991.

Publisher's Note Springer Nature remains neutral with regard to jurisdictional claims in published maps and institutional affiliations. 